Article

\title{
Non-Destructive Tests for Damage Evaluation of Stone Columns: The Case Study of Sacro Monte in Ghiffa (Italy)
}

\author{
Alessandro Grazzini *(D), Sara Fasana, Marco Zerbinatti and Giuseppe Lacidogna \\ Department of Structural Geotechnical and Building Engineering, Politecnico di Torino, 10138 Torino, Italy; \\ sara.fasana@polito.it (S.F.); marco.zerbinatti@polito.it (M.Z.); giuseppe.lacidogna@polito.it (G.L.) \\ * Correspondence: alessandro.grazzini@polito.it
}

Received: 29 February 2020; Accepted: 10 April 2020; Published: 13 April 2020

check for updates

\begin{abstract}
The Italian Sacri Monti are heritage sites with some unique characteristics; they are a successful symbiosis between nature and art and are unconfined structures, therefore always being accessible but exposed to atmospheric agents, with many relevant consequences with regard to conservation problems. The paper discusses some aspects related to the application of non-destructive techniques (NDT) for the interpretation of degradation phenomena occurring in stone structural elements. Ultrasonic and impact tests were used to evaluate the structural properties of the stone columns in the Via Crucis portico, within the monumental complex of the Sacro Monte in Ghiffa (Piedmont, Italy), in order to determine their conditions of maintenance and to evaluate the portico static stability. Ultrasonic tests made it possible to obtain the value of the dynamic elastic modulus, which was variable at different points of the columns due to the diversified level of material damage. The impact test, performed with an instrumented hammer in the same points of the ultrasonic test, enables, by comparison, a deeper knowledge of the surface resistance of damaged columns. These results are the first step in a research path that will require further laboratory tests to better calibrate the diagnostic techniques applied to different levels of damage to surface materials.
\end{abstract}

Keywords: non-destructive techniques (NDT); historical buildings; maintenance; stone columns; ultrasonic test; impact test

\section{Introduction}

Historical architectural heritage requires specific maintenance and restoration interventions, especially in the presence of prolonged deterioration over time. Restoration works may control deteriorations, which can affect monuments, without secondary effects on treated surfaces of the historical elements [1-5]. Similarly, diagnostics, which is a fundamental phase of knowledge in order to deepen the critical aspects of structure assessments and degradation causes, must operate with technologies that can be used in a non-destructive and non-invasive way for the historical buildings [6-13]. The main purposes related to the general framework of the material maintenance conditions are those to refine methodological paths for such contexts, to have well-founded analytical support and to reduce the error range in the qualitative and quantitative evaluation of the damage process. Ultrasonic tests are one of the non-destructive techniques most often used in the field of diagnostics on historical buildings [14-16]. They measure the wave speed through the material thickness, which is in relation to the dynamic elastic modulus. The results obtained by tests on architectural heritage are representative, if compared with known physical characteristics of similar materials, of the degradation inside the structural section of historical elements. In addition, the impact tests, performed with an instrumented hammer in the same points of the ultrasonic test, enable the evaluation of the surface degradation level [17]. 
This research concerns the mechanical characterization, through non-destructive techniques (NDT), of the 13 stone columns (granitoid rock) that support the Via Crucis portico inside the monumental complex of the Sacro Monte in Ghiffa. The Sacri Monti of northern Italy are a UNESCO heritage site that includes nine complexes that constitute groups of chapels and other buildings with many artistic masterpieces. All buildings are part of a high-quality natural environment. The first complex was founded in the late 15th century in Varallo Sesia, and the others were constructed up to the end of 17th century and dedicated to different aspects of the Christian faith [18]. In addition to their symbolic spiritual meaning, they are of great beauty by virtue of the skill with which they have been integrated into the surrounding natural landscape of hills, forests and lakes. They also house much important artistic material in the form of wall paintings and statuary.

Many buildings within the Sacri Monti monumental complexes suffer from different conditions of degradation, linked in particular to the climatic conditions of moisture, rain, damp action from capillary rising, freeze-thaw cycles that cause the detachment of plaster and the degradation of the stone elements [19]. A research group of the Politecnico di Torino has been interested for years in the study of non-destructive diagnostic techniques for the evaluation of degradation levels of the architectural and structural elements of historical buildings in the Sacri Monti complexes [1,20-23].

In the specific case of the Sacro Monte at Ghiffa, the Via Crucis portico (Figure 1) is supported by 13 stone columns with evident intense superficial material degradation. The portico was built between 1752 and 1761. It is marked by 14 spans and has columns and capitals made by stones derived both from local "granitic stones". It is possible that the origin of the stone of columns is not from historical quarries but from erratic boulders found near the construction site (aplite is the current interpretation, but other investigations are in progress), referred to in slang as "trovanti", while for the capitals there is a strong similarity with a serizzo quarried near Locarno (Valle Verzasca, Switzerland) (Figure 2). Considering a macroscopic mineralogical analysis with a 10x magnifying glass, the rock is mainly made up of more than $90 \%$ of crystalline clear silica minerals (quartz and feldspar), with little biotitic dark mica and rare light mica. The main accessory mineral is a small red-vined garnet that characterizes the stone. The veins present confirm the low quality of the stone, almost certainly extracted from makeshift material, greatly influencing the variability of mechanical characteristics. Perhaps, also for the lower quality, it is very prone to degradation phenomena, worsened by atmospheric moisture, the presence of salts, freeze-thaw cycles and thermal expansion, which is also due to strong summer radiation, which can produce erosion and exfoliation on the stone surface [24,25] (Figure 3). The material degradation is increasing from the inside to the outside of the structural section of the columns, and the result is a decay of their compressive strength, the residual value of which needs to be investigated.

The aim of the ongoing research is to deepen the knowledge of the mechanical characteristics of the columns of the Via Crucis portico resulting from degradation, to estimate their residual strength. In order to improve the maintenance and conservation planning of the historical buildings belonging to the Sacri Monti monumental complex, some non-destructive tests were carried out on the columns of the portico to investigate the elastic modulus of the stone. Specifically, the ultrasonic technique was used, associated with that of impacts for a more precise comparison of the stone surface degradation. From the value of the dynamic elastic modulus, it was possible to estimate the compressive strength of each single column using experimental reports. As a matter of fact, the ultrasonic and impact tests showed a great variability of the elastic modulus already within the same column and between columns. This variability was the demonstration of a material degradation distributed unevenly within the same stone element and between the columns. 


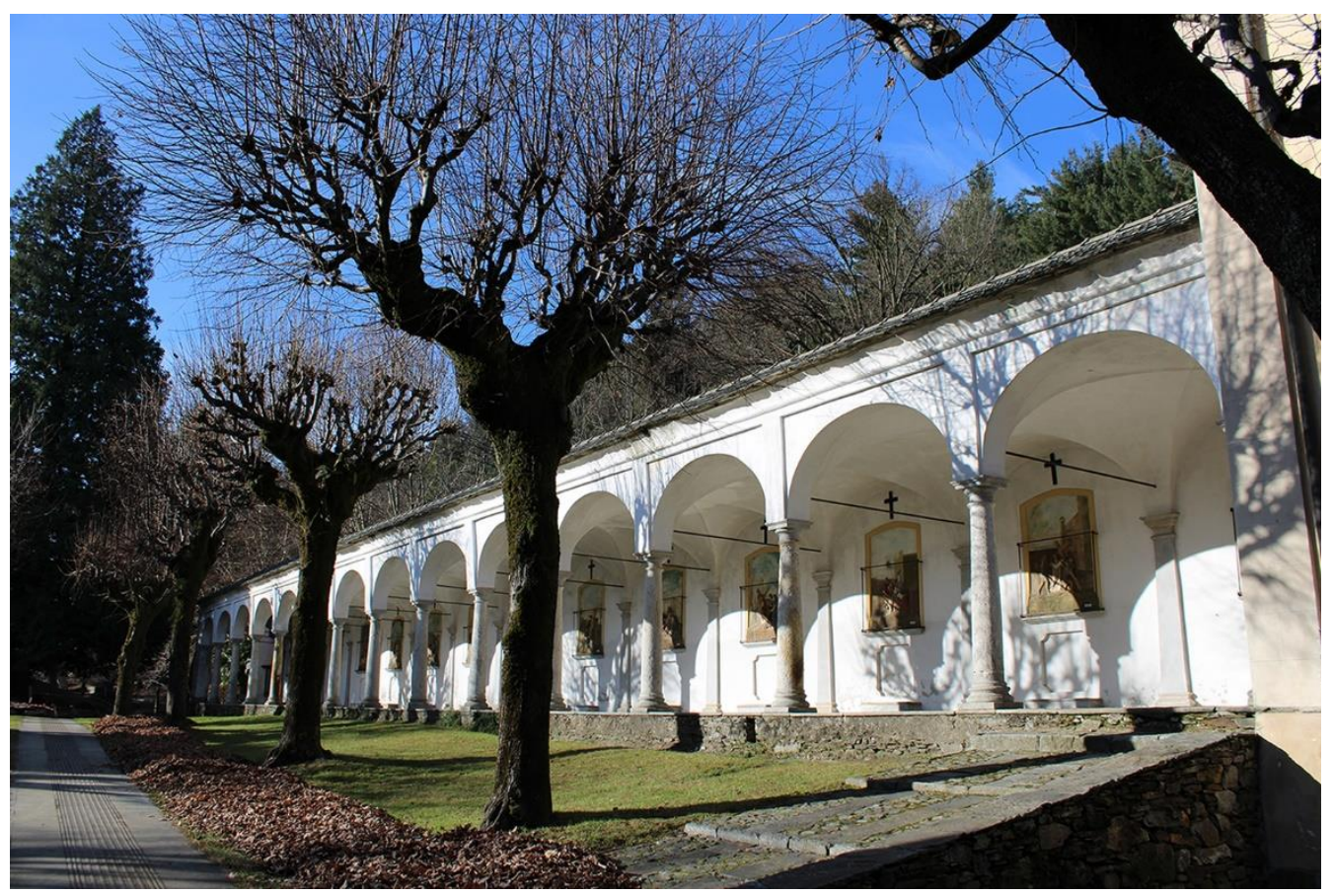

Figure 1. The Via Crucis portico inside the Sacro Monte of Ghiffa (Piedmont, Italy).

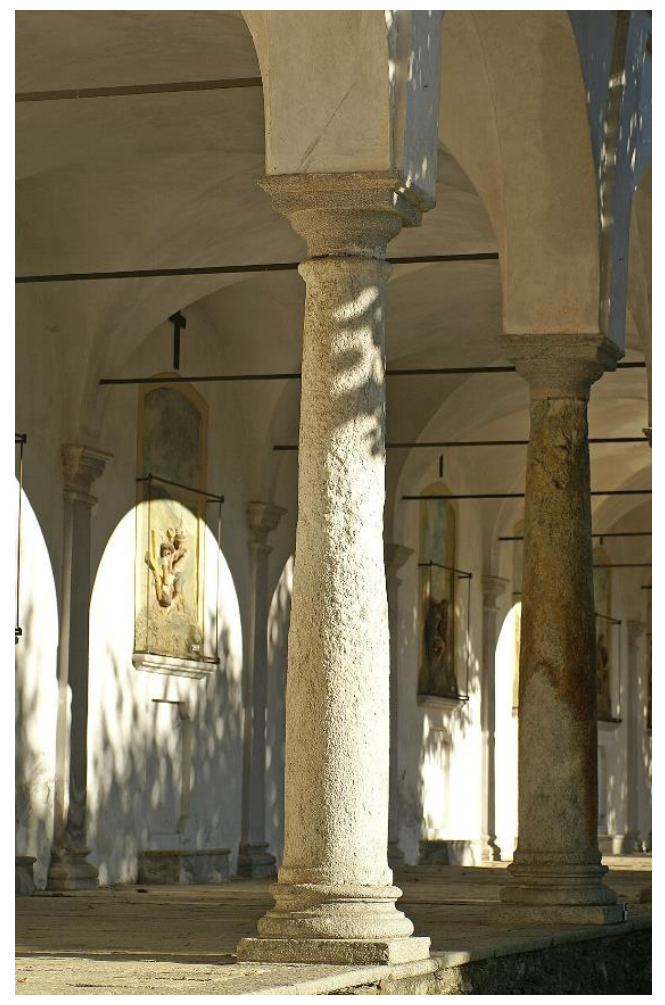

Figure 2. The stone columns of the Via Crucis portico in the Sacro Monte at Ghiffa. 


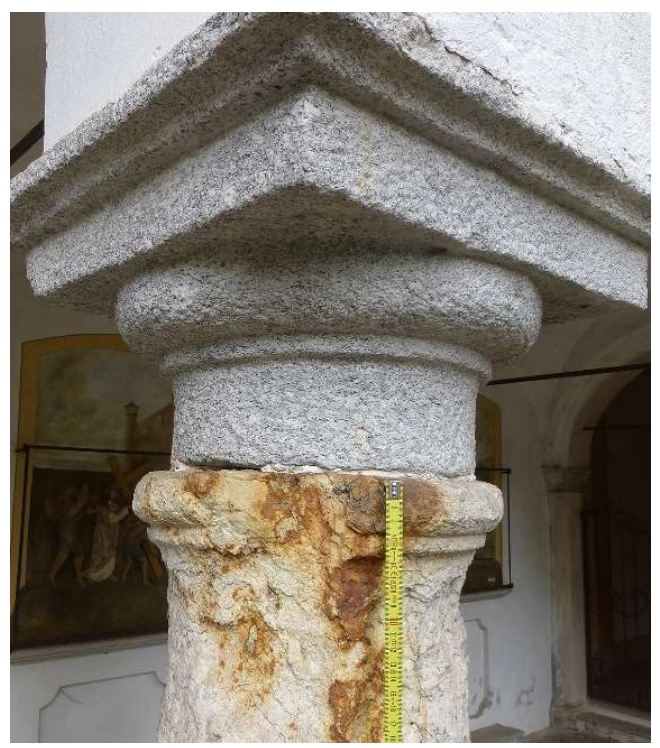

(a)

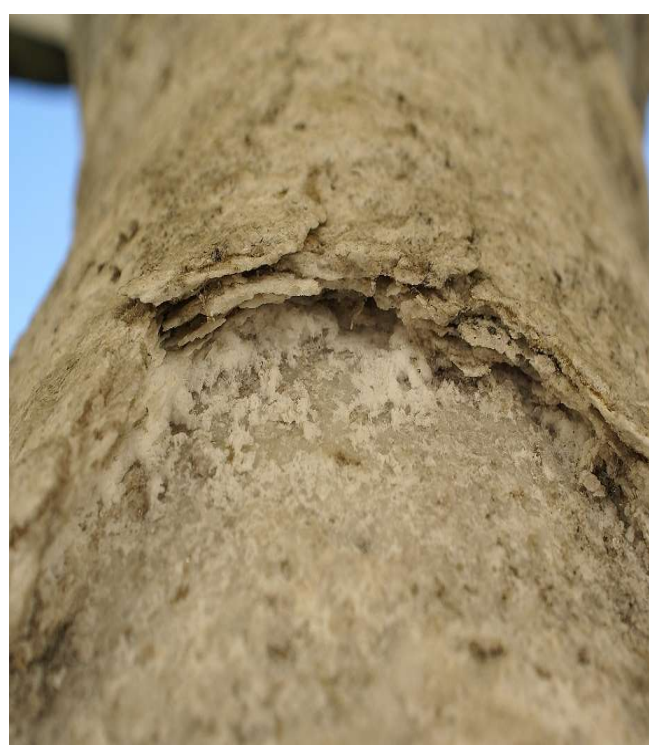

(b)

Figure 3. Examples of erosion (a), exfoliation and detachment (b) problems in stone columns of the Via Crucis portico. The reference lexicon is that of the "Ente Nazionale Italiano di Unificazione" (UNI) Standard rules 11182:2006.

These results could be used in forthcoming finite element numerical modeling of the portico, in order to evaluate its stability in the hypothesis of replacing the current roof covering, made with lighter modern stones slabs, by traditional roof covering made by more heavy ones. The assessments that emerged from these diagnostic tests will also be useful for future maintenance work planned for the conservation of the Via Crucis portico; the diagnostic procedure proposed could then be extended to investigate for the various degradation problems afflicting the historical buildings of Sacri Monti monumental complexes.

The experimental results described represent a first phase of the research, which will be subsequently extended to similar types of stones obtained from quarries on which to perform compression tests in the laboratory and related non-destructive tests (ultrasonic and impact). In this way it will be possible to calibrate the non-destructive techniques, which will then be more frequently used in situ on valuable architectural elements.

\section{Materials and Methods}

Each column was investigated at the bottom, center and top by an ultrasonic test and subsequently at the same points by an impact test. The choice of the points was based above all on a visual examination, comparing points where the material degradation was evident with those in which the stone seemed in better condition (the columns were also struck with light plastic hammers to hear their "sound"). Both were non-destructive investigation techniques that adapt very well to analyze the architectural element under investigation. The goal was to obtain the value of the elastic modulus and to evaluate the quality of the resistant stone section subject to degradation. The test was also an opportunity to compare the results of the ultrasonic test, useful for investigating the entire length of the stone section, with those obtained from the impact test, which, on the contrary, estimates the material characteristic deformation by analyzing only the external surface on which the hit is performed.

\subsection{Ultrasonic Test}

The ultrasonic test device consisted of a Proceq Pundit PL-200 ${ }^{\circledR}$ pulse generator $(0.1-7930 \mu \mathrm{s}$ range; resolution of $0.1 \mu$ s for pulse speed $<793 \mu \mathrm{s}, 1 \mu$ s for pulse speed $>793 \mu$ s; impulse voltage $100-450 \mathrm{Vpp}$ ); two transducers of $54 \mathrm{kHz}$, one emitting and the other receiving; a pulse amplifier and 
an electronic device for measuring the time interval. On the basis of the time taken by the wave to travel the distance between the two transducers, the propagation speed of the elastic waves through the stone material of the column is calculated. The speed propagation of the waves in a homogeneous material depends on its density and elastic characteristics (elastic modulus, Poisson's ratio), closely related to the quality and compressive strength of the material itself. The speed of the wave is in fact low if the material has voids, cracks or detachments that slow down the path; vice versa, it is high if the material is compact and homogeneous, demonstrating good quality. The measurement of the propagation time of the ultrasonic pulses was carried out with the use of two transducers, applied on the surface of the elements involved in the control.

Direct tests were carried out by positioning the transducers on the two opposite faces of the element under investigation, as indicated in Figure 4. The coupling of the transducer on the stone surface was facilitated through the application of a thin layer of modeling clay in order to avoid air interpositions and facilitate the transmission of the wave in the material. The measurements were conducted in accordance with the methods proposed in American Society for Testing and Materials (ASTM) rules D2845 1995 and in Ente Nazionale Italiano di Unificazione, Comité Européen de Normalisation, (UNI EN) rules 12504-4: 2005 [26,27]. The tests are based on the determination of the propagation speed $(v)$ of the pulses of the ultrasonic longitudinal waves in the material, the values of which, in the first approximation, are related to the dynamic modulus $\left(E_{d}\right)$ of the material, which consequently is related to its mechanical strength [16]:

$$
E_{d}=v^{2} \rho \frac{(1+v)(1-2 v)}{(1-v)}
$$

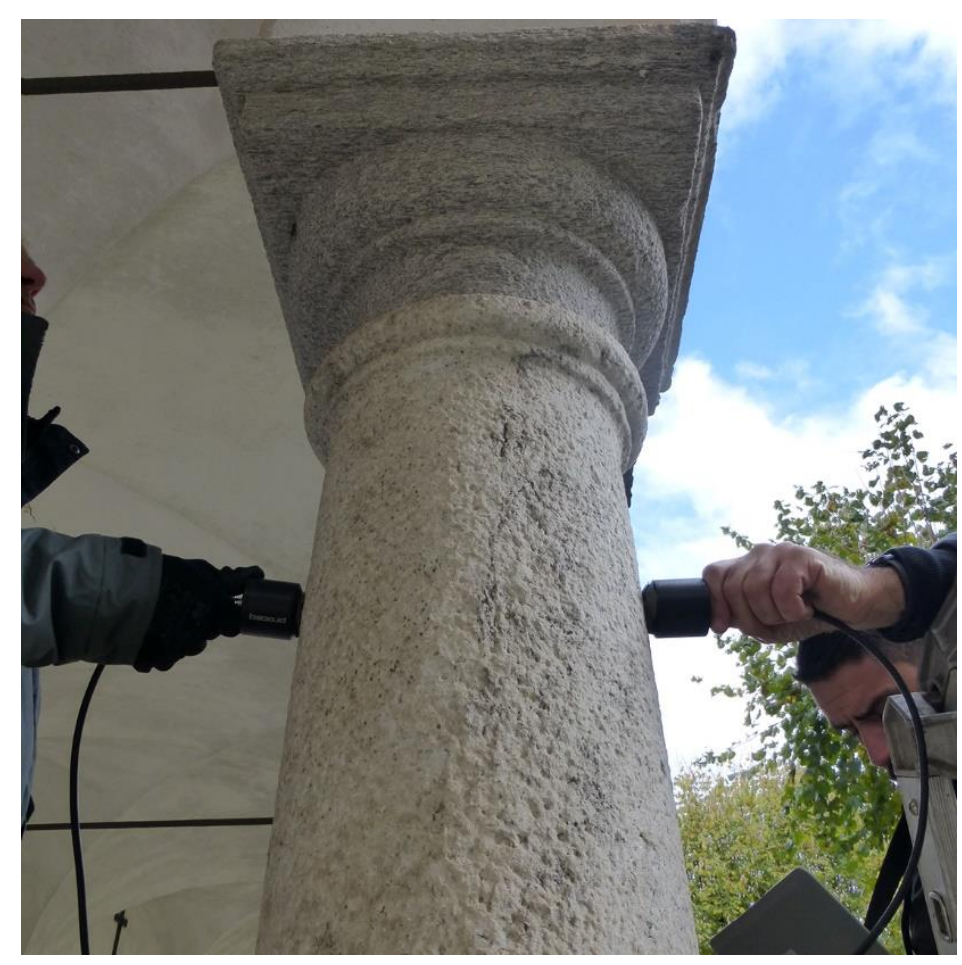

Figure 4. Ultrasonic test carried out on columns of Via Crucis, Ghiffa.

In Equation (1), $\rho$ is the density of material, and $v$ is Poisson's ratio. In this case, from scientific literature sources, a $\rho$ value equal to $2630 \mathrm{daN} / \mathrm{m}^{3}$ and a $v$ value equal to 0.18 were considered [28]. 


\subsection{Impact Test}

The impact test was performed using an instrumented hammer capable of generating an impact, with a known mass and predetermined energy, against the surface of the stone. The software that analyzes the data is able to return the force-time diagram of each impact. This type of test, unlike other impulsive methods, allows the evaluation of the evolution over time of the forces acting in the impact. For example, the sclerometer test detects only the elastic energy returned by the concrete after the impact. On the other hand, the impact test also evaluates the given energy, the dissipated energy, the impact time and the maximum force. It therefore represents a non-destructive technique for evaluating the elastic and inelastic properties of materials. $[17,29]$. The analysis of the diagram $(F, t)$ can obtain the value of the homogeneous material elastic modulus through Hertz's impact theory [29-31] (see Appendix A).

The electric impact hammer (Figure 5) is a device produced by Piezotronic PCB Inc Company (Depew, NY, USA). It is characterized by a variable force from $44.48 \mathrm{~N}$ to $4448.26 \mathrm{~N}$, and a force sensor sensitivity of $2.47 \mathrm{mV} / \mathrm{N}$. It performs the impact of a $10 \mathrm{~mm}$ diameter steel ball with a total mass of 207 grams, connected to a piezoelectric pulse transducer. The impact is generated by the hammer by means of a predetermined energy, characterized by a level of amplifier and impedance adapter. The acquisition is performed by a Pimento model multichannel LMS signal analyzer (Figure 5).

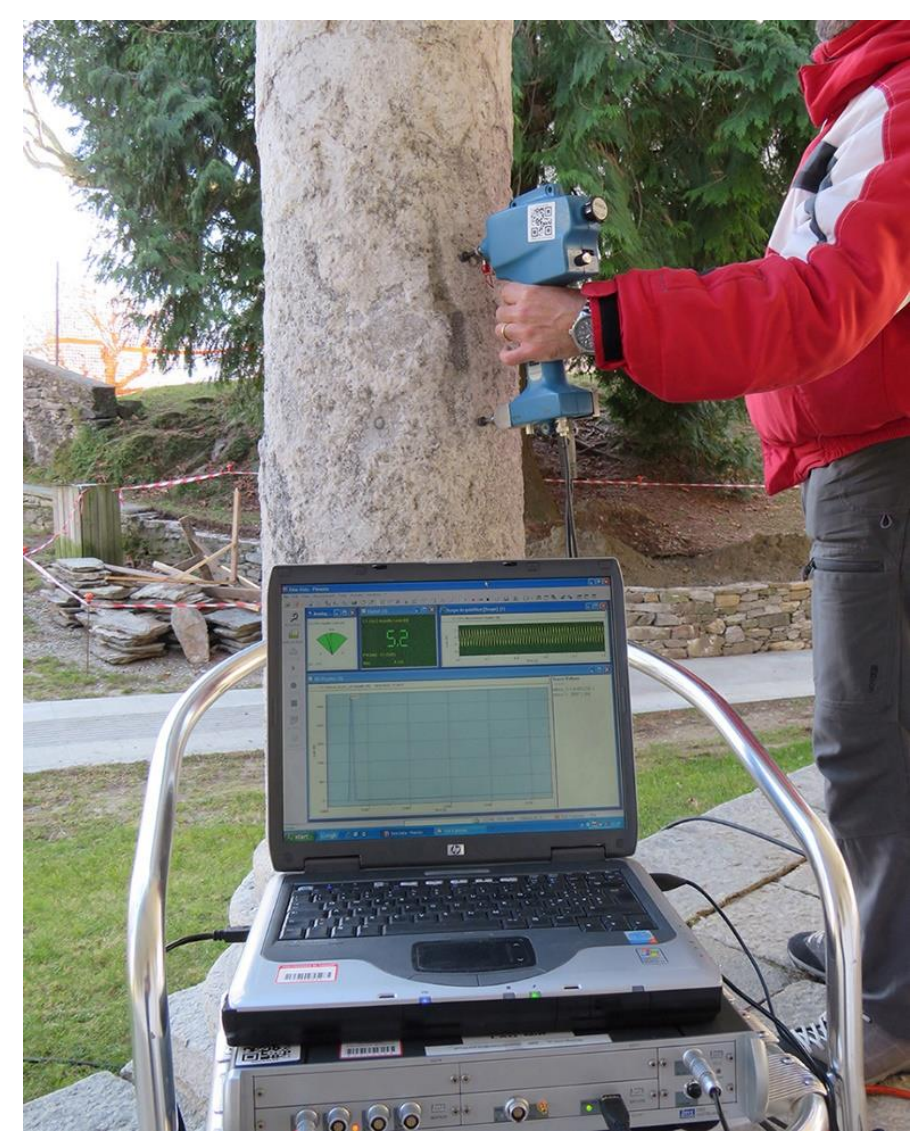

Figure 5. Setup of the impact test.

The hammer was positioned perpendicular to the surface to be investigated. Perpendicularity alignment was achieved thanks to four fixed metal brackets. The impact of the small impact mass was generated by pressing a trigger on the electric hammer. The intensity of the impact is very low and therefore not invasive even for surfaces of artistic value. The elastic modulus of the stone was 
determined according to the classical theory of the elastic collision between two bodies elaborated by Hertz [17,29-31], using the following equations:

$$
E_{s}=\frac{E^{*} E_{0}\left(1-v^{2}\right)}{E_{0}+E^{*}\left(v_{0}^{2}-1\right)}
$$

where $E^{*}$ was obtained by:

$$
E^{*}=\sqrt{\left(\frac{2,87}{T}\right)^{5} \frac{m^{3}}{R A_{1}}}
$$

The parameters in Equations (2) and (3) are the following: A1 is the area beneath the diagram $(F, t)$ (see Figure 6), $T$ represents the time in which the contact occurs between the two surfaces; $R$ is the radius of curvature $(10 \mathrm{~mm})$ of the impact mass $m(0.207 \mathrm{Kg}), E_{0}$ is the mass elastic modulus $(222,000 \mathrm{MPa})$ and $v_{0}$ is its Poisson's ratio (0.2), while, with regard to the stone material of the columns, a Poisson's ratio $v$ of 0.18 was considered [28].

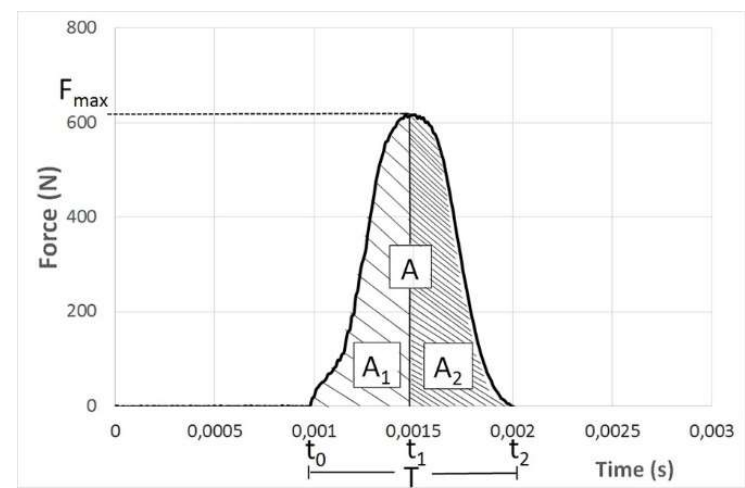

(a)

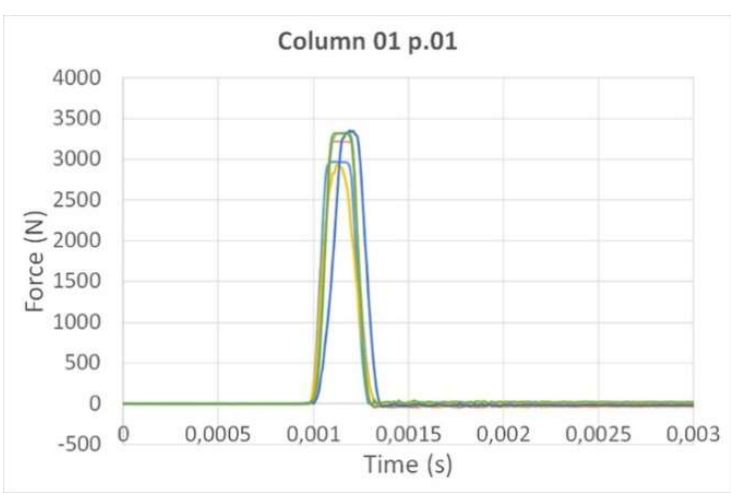

(b)

Figure 6. (a) Generic force-time diagram of an impact test; (b) test results by impact test on column 1 of the portico.

\section{Results}

The diagnostic study of the structural characteristics of the columns of the Via Crucis portico was mainly based on the execution of ultrasonic tests, which were followed by impact tests at the same points. While the ultrasonic tests enable the evaluation of the dynamic elastic modulus of the columns by measuring the speed pulses, the impact tests investigate the material degradation on the surface of the columns (the detachment points of material, for example).

\subsection{Ultrasonic Tests}

The ultrasonic tests were carried out on all the columns of the Via Crucis portico on 1-3 points each (depending on the visual level of degradation), in order to have an average of the speed pulses and the related dynamic modulus over the entire height of the column. As can be seen from the results of Table 1, the columns showed highly variable values of the dynamic modulus, sometimes even on the same column. This variability confirmed the diversified state of material degradation to which the columns were subjected in relation with the alteration of the original natural stone used (Figure 7). Through Correlation Curve (4), experimentally obtained by Vasconcelos et al. [16], it was possible to estimate the compressive strength, $f_{c}$, of the granitoid rock from the value of the dynamic modulus. The $f_{c}$ value obtained by the experimental correlation laws represents an estimation (the values of which fall within the ranges present in the scientific literature), pending a better confirmation from subsequent tests that will be carried out in the laboratory. These tests will provide the compression 
stress results on samples taken from erratic stones present in the area, made of the same material as that of the columns.

$$
f_{c}=0.0407 v-36.31
$$

Table 1. Values of dynamic modulus by ultrasonic tests on Via Crucis portico columns.

\begin{tabular}{|c|c|c|c|c|c|}
\hline Column & Test Point & Height (cm) & $\mathrm{v}(\mathrm{m} / \mathrm{s})$ & $\mathrm{E}_{\mathrm{d}}(\mathrm{MPa})$ & $\mathrm{f}_{\mathrm{c}}(\mathrm{MPa})^{2}$ \\
\hline \multirow{3}{*}{1} & 1 & 57 & 3269 & 25,878 & 97 \\
\hline & 2 & 98 & 2503 & 15,170 & 66 \\
\hline & 3 & 230 & 2805 & 19064 & 78 \\
\hline \multirow{3}{*}{2} & 1 & 65 & 3411 & 28,183 & 103 \\
\hline & 2 & 123 & 2466 & 14,728 & 64 \\
\hline & 3 & 223 & 2494 & 15,067 & 65 \\
\hline \multirow{2}{*}{3} & 1 & 70 & 2910 & 20,506 & 82 \\
\hline & 2 & 230 & 2939 & 25,406 & 96 \\
\hline \multirow{2}{*}{4} & 1 & 60 & 4024 & 39,219 & 127 \\
\hline & 2 & 232 & 3908 & 36,985 & 123 \\
\hline \multirow{2}{*}{5} & 1 & 68 & 2724 & 17,972 & 75 \\
\hline & 2 & 228 & 2738 & 18,156 & 75 \\
\hline 6 & 1 & 55 & 2766 & 18,525 & 76 \\
\hline \multirow{2}{*}{7} & 1 & 86 & 3402 & 28,033 & 102 \\
\hline & 2 & 206 & 2948 & 21,046 & 84 \\
\hline \multirow{2}{*}{8} & 1 & 86 & 2774 & 18,644 & 77 \\
\hline & 2 & 229 & 3223 & 25,158 & 95 \\
\hline 9 & 1 & 146 & 2495 & 15,080 & 65 \\
\hline \multirow{2}{*}{10} & 1 & 100 & 2522 & 15,406 & 66 \\
\hline & 2 & 228 & 2756 & 18,402 & 76 \\
\hline \multirow{2}{*}{11} & 1 & 101 & 2698 & 17,627 & 73 \\
\hline & 2 & 204 & 2773 & 18,629 & 77 \\
\hline \multirow{2}{*}{12} & 1 & 90 & 2965 & 21,300 & 84 \\
\hline & 2 & 190 & 3178 & 24,468 & 93 \\
\hline \multirow{3}{*}{13} & 1 & 35 & 4638 & $52,111^{1}$ & $152^{1}$ \\
\hline & 2 & 130 & 2840 & 19,532 & 79 \\
\hline & 3 & 224 & 3149 & 24,024 & 92 \\
\hline
\end{tabular}

${ }^{1}$ Basic element of the column made of different stone materials of better quality. ${ }^{2}$ Estimated according to the correlation curve of Vasconcelos et al. [13].

\subsection{Impact Tests}

The purpose of the impact test was to verify the surface resistance of the stone elements, considering their surface degradation. The impact test, when performed on homogeneous material such as concrete or stone, can provide through Equation (2) values of the elastic modulus completely comparable to those obtained by the ultrasonic technique [29]. It should be remembered that the value obtained with the impact test represents a static elastic modulus $\left(E_{s}\right)$, the conversion of which into a dynamic value deserves separate research considering the many different formulas present in scientific literature for the different types of stones and rocks [32]. To obtain a correct and reliable correlation formula for each type of stone, a large number of tests must be performed in the laboratory and correlated with non-destructive tests; this correlation could then be calibrated as a suitable diagnostic technology to be applied on specific architectural elements. However, since the test is based on an energetic evaluation relative to the impact on the surface of the element (Figure 8), in presence of a surface degradation, 
like the one found in situ, it does not provide elastic modulus values that can be correlated with those obtained by ultrasonic tests.

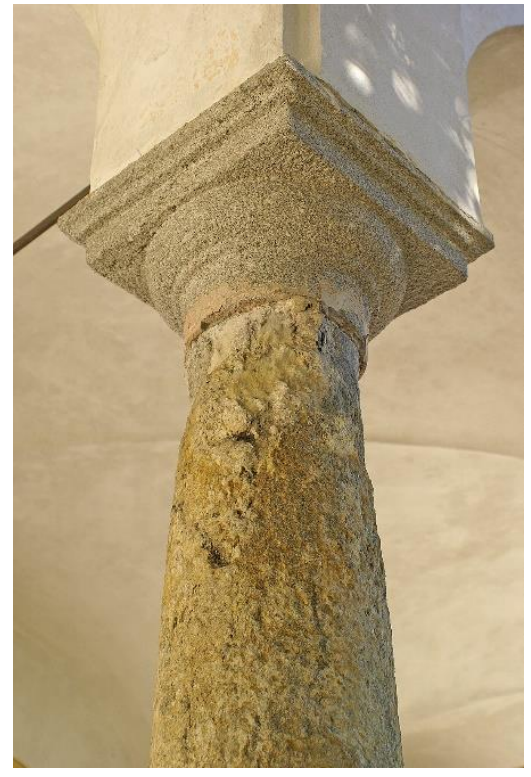

(a)
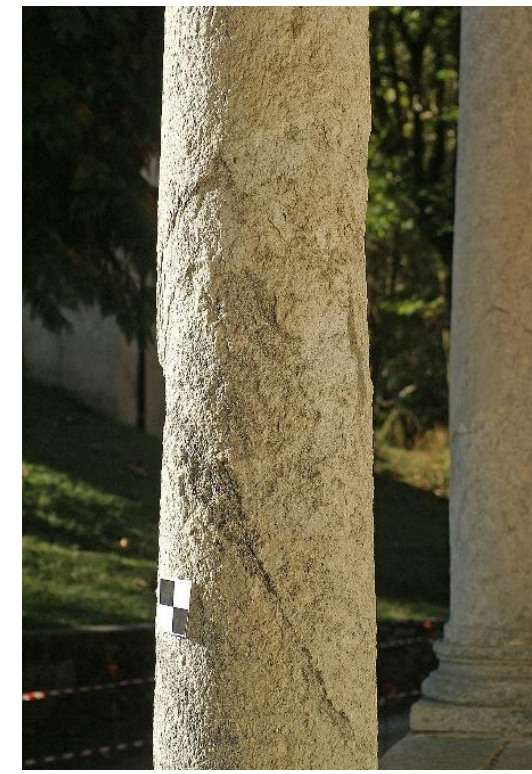

(b)

Figure 7. Different types of surface material degradation on the columns of the Via Crucis portico: (a) erosion; (b) exfoliation.

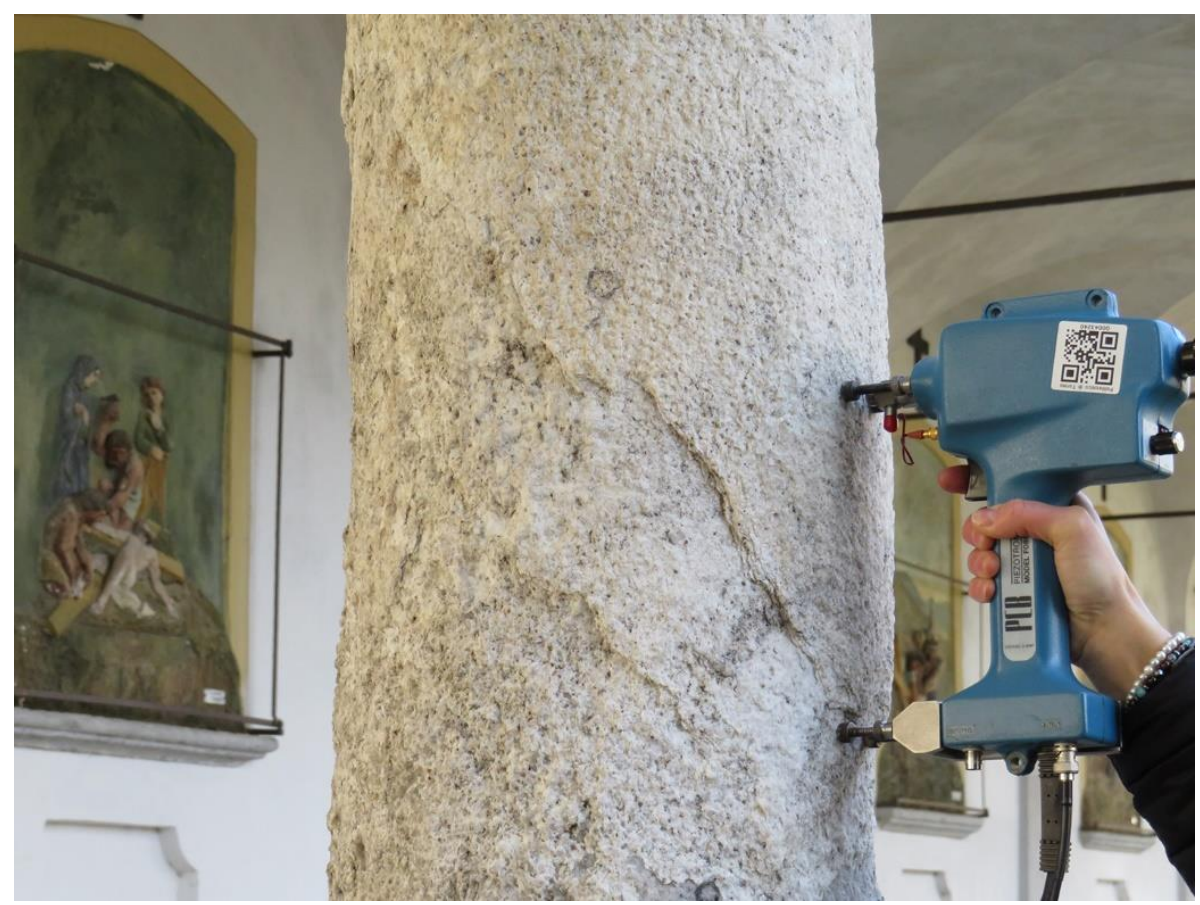

Figure 8. Impact test carried out on a column of Via Crucis portico.

Figure 9 shows, for example, the time-force curves between two different points of the same test on column 3. In presence of surface degradation, the curves are characterized by lower peak force and wider response times. The ratio between the returned $A_{2}$ and supplied energy $A_{1}$ (Figure 6a) provided indications regarding the detachment of the degraded matter crust $[17,33]$. 


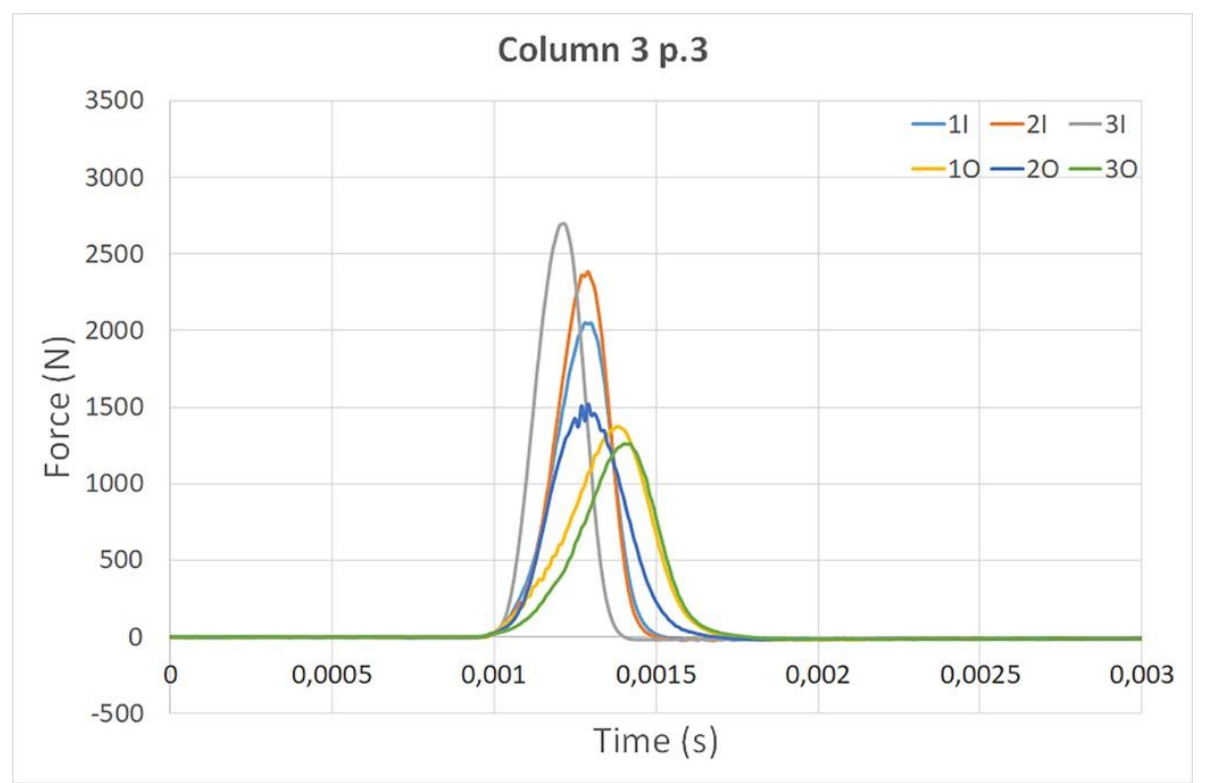

Figure 9. Time-force diagrams of third point of column 3 ( $\mathrm{I}=$ point inside of the portico; $\mathrm{O}=$ outside of the portico).

With reference to the values of the dynamic elastic modulus, Figure 10 reports, for example, the dispersion of the data collected in the impact tests on the columns at Ghiffa and the same comparison obtained from the similar type of homogeneous and non-degraded stone tested in the laboratory.

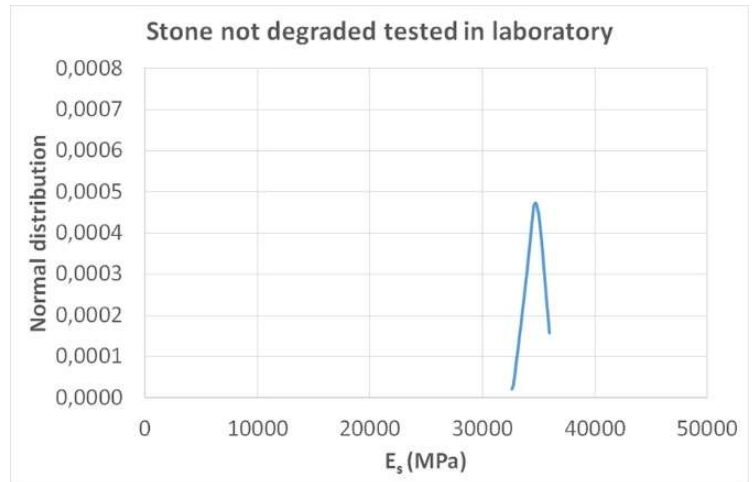

(a)

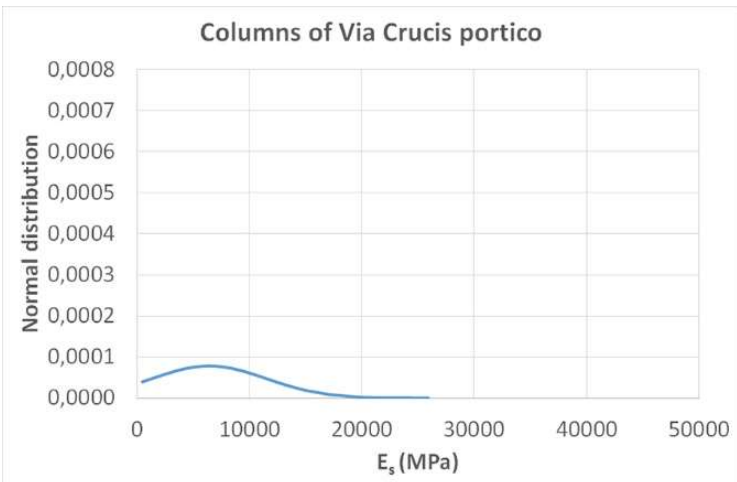

(b)

Figure 10. Gaussian distribution $E_{S}$ of non-degraded stone (a) and of the same type of stone degraded in the columns of the Via Crucis portico at Ghiffa (b).

From Figure 10, a significant difference can be seen between the two Gaussian curves. The one relating to laboratory tests on a sample of new stone similar to that used in the Ghiffa columns revealed a significantly lower standard deviation $\sigma$ than that detected with the impact tests performed in situ on the columns of the Via Crucis portico. The differences are due to the considerable diversification of the material degradation affecting the surface of the columns. Similarly, Table 2 shows the results provided by impact tests on the new stone in the laboratory and on the old in situ columns of the Via Crucis portico. 
Table 2. Impact tests on new and old granitic stones.

\begin{tabular}{ccc}
\hline Stone & $\mathbf{E}_{\text {s average }}(\mathbf{M P a})$ & $\sigma(\mathbf{M P a})$ \\
\hline New stone in the laboratory & 34,711 & 843 \\
Old stone of the columns & 6394 & 5100 \\
\hline
\end{tabular}

\section{Discussion}

The in situ diagnostic tests and their comparison in the laboratory show how dispersive the results of the ultrasonic and impact tests can be when applied to architectural elements in a degraded state. The surface roughness of ancient in situ elements affects the impact test results, not allowing a good correlation with the values of the dynamic elastic modulus obtained from the ultrasonic tests. On the contrary, the same tests performed in the laboratory on a sample of new and unaltered stone show a very good correlation between the dynamic elastic modulus obtained from the ultrasonic tests and the static modulus obtained from the impact test, both with a Gaussian curve characterized by very small standard deviations.

The ultrasonic tests recorded speed waves average values of about $3000 \mathrm{~m} / \mathrm{s}$ (Table 3), which the scientific and experimental literature [16,28] classifies as medium quality material. However, there is a high variability of the values derived from the material degradation level (not excluding the original alteration of the quarried material, from upper part of the extraction site, or by single big rocks like the "trovanti"), from possible detachments or exfoliation of surface material. The speeds measured on the same type of not degraded stone obtained from the quarry detected higher values (albeit with little difference) and statistically more stable speed values (Table 3). The standard deviation value was representative of the material degradation of the stone surface on which the ultrasonic and impact tests were performed. In this case, both were characterized by a high value of the standard deviation due to the diversified level of material degradation that characterizes the columns of the Via Crucis portico (Figures 10b and 11b). Vice versa, as is visible in Tables 2 and 3 and in Figures 10a and 11a, corresponding to the same stone, though intact and without any material alteration, there was a very low value of the standard deviation and a good correlation between the values of the elastic modulus obtained from both types of non-destructive tests.

Table 3. Ultrasonic tests on new and old stones.

\begin{tabular}{cccc}
\hline Stone & $\mathbf{V}_{\text {average }}(\mathbf{m} / \mathbf{s})$ & $\mathbf{E}_{\mathbf{d} \text { average }}(\mathbf{M P a})$ & $\boldsymbol{\sigma}(\mathbf{M P a})$ \\
\hline New stone in the laboratory & 3498 & 29,640 & 611 \\
Old stone of the columns & 2961 & 21,623 & 6183 \\
\hline
\end{tabular}

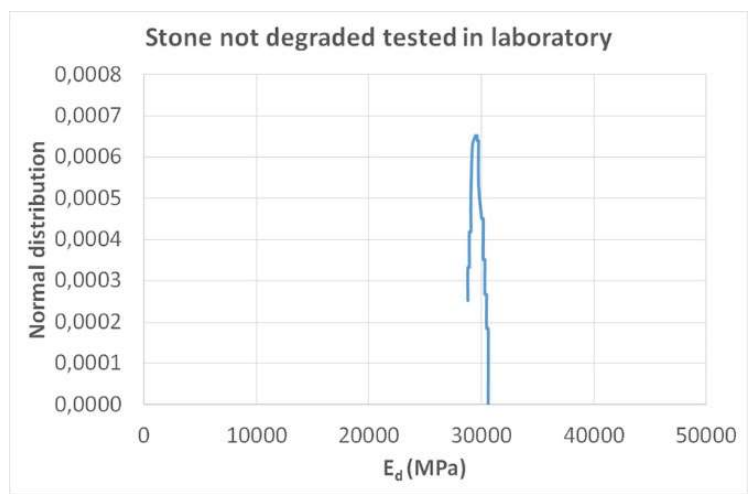

(a)

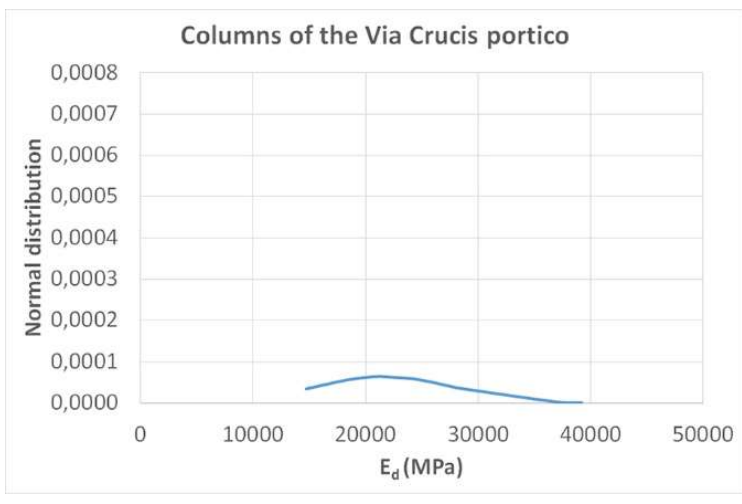

(b)

Figure 11. Gaussian distribution $\mathrm{E}_{\mathrm{d}}$ of non-degraded stone (a) and of the same type of stone degraded in the columns of the Via Crucis portico at Ghiffa (b). 


\section{Conclusions}

The experimental research carried out in situ to determine the residual strength of the degraded stone columns of the Via Crucis portico at the Sacro Monte of Ghiffa is a first step in a research path that aims to calibrating non-destructive techniques for the diagnosis of heritage monument degradation. Ultrasonic and impact techniques were used, critically analyzing their correlation in the presence of surface material degradation. The ultrasonic test highlighted the variability of the dynamic elastic modulus within the same columns, while the impact test highlighted the local points of surface material degradation. Many other tests in the laboratory and in situ will be needed, on different types of stones, to correlate the values of dynamic elastic modulus obtained by the ultrasonic technique with the static one that resulted from the impact tests. Subsequent laboratory tests will be also planned to calibrate the impact test applied to different levels of surface material damage, in order to find correlations with the values of dynamic elastic modulus obtained from ultrasonic tests.

Author Contributions: Conceptualization, A.G., M.Z., S.F. and G.L.; In situ tests, S.F., M.Z. and A.G.; Writing A.G., S.F.; Supervision, M.Z. and G.L.; Project administration, M.Z. All authors have read and agreed to the published version of the manuscript.

Funding: This research was funded by MAIN10ANCE Interreg Project.

Acknowledgments: The authors would like to thank Giovanni Bricca and Franco Grindatto for their valuable technical support during the execution of the in situ tests. The authors also wish to thank Josè Delgado Rodrigues for his precious visit and petrographic consultancy at the Sacro Monte of Ghiffa.

Conflicts of Interest: The authors declare no conflict of interest.

\section{Appendix A}

Hertz's theory of the elastic collision between two bodies in the absence of friction is modeled according to the scheme in Figure A1, where a sphere of radius $\mathrm{R}$ impacts with velocity $v_{0}$ penetrating with a depth $\delta$ in an elastic semi-infinite space [27]:

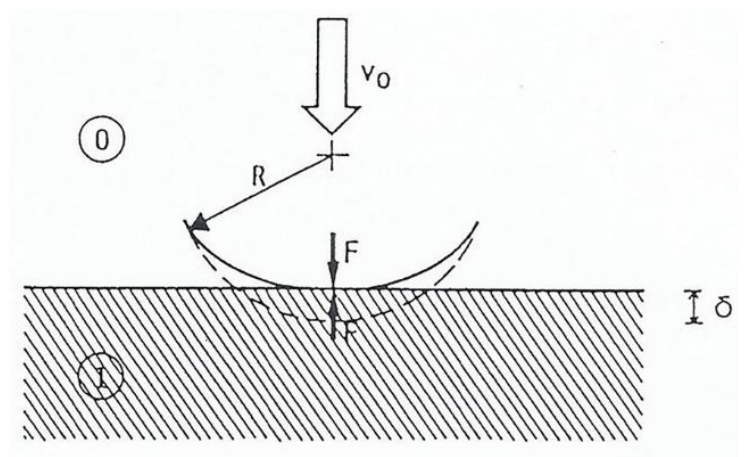

Figure A1. Impact between the moving mass and the elastic semi-infinite surface.

The depth of indentation is:

$$
\delta=\left(\frac{9 F^{2}}{16 R E^{* 2}}\right)^{\frac{1}{3}}
$$

The applied force $F$ is related to the displacement $\delta$ by:

$$
F=\frac{4}{3} R^{\frac{1}{2}} E^{*} \delta^{\frac{3}{2}}=K \delta^{\frac{3}{2}}
$$

where

$$
\frac{1}{E^{*}}=\frac{1-v_{0}^{2}}{E_{0}}+\frac{1-v_{1}^{2}}{E_{1}}
$$


and $v_{0}, v_{1}, E_{0}$ and $E_{1}$ are, respectively, Poisson's ratios and the elastic moduli associated with the sphere (0) and the semi-infinite space (1).

Considering that the sphere impacts on the surface in the initial time with a speed $v_{0}$, and that $v_{1}$ is the speed in the next instant, the following equation can be written:

$$
m \frac{d v}{d t}=m \frac{d^{2} \delta}{d t^{2}}=-F
$$

and from (A1) and from (A4):

$$
m \frac{d^{2} \delta}{d t^{2}}=-\frac{4}{3} R^{\frac{1}{2}} E^{*} \delta^{\frac{3}{2}}
$$

Through integration, the following can be achieved:

$$
\frac{1}{2}\left[v_{0}^{2}-\left(\frac{d \delta}{d t}\right)^{2}\right]=\frac{2 K \delta^{\frac{5}{2}}}{5 m}
$$

where $K$ is the value indicated in (A2).

The maximum depth of indentation $\delta^{*}$ occurs in the case of $\frac{d \delta}{d t}=0$, for which:

$$
\delta^{*}=\left(\frac{5 m v_{0}^{2}}{4 K}\right)^{\frac{2}{5}}=\left(\frac{15 m v_{0}^{2}}{16 E^{*} R^{\frac{1}{2}}}\right)^{\frac{2}{5}} .
$$

The diagram $(F, t)$ in the compression phase can be obtained by means of a second integration:

$$
t=\frac{\delta^{*}}{v_{0}} \int \frac{d\left(\delta / \delta^{*}\right)}{\left[1-\left(\delta / \delta^{*}\right)^{\frac{5}{2}}\right]^{\frac{1}{2}}} .
$$

The instant $t^{*}$, corresponding to the maximum depth of the deformation $\delta^{*}$ during the impact, referred to as time $t_{1}$ in Figure $6 a$, is given by the following equation:

$$
t^{*}=\frac{\delta^{*}}{v_{0}} \int \frac{d\left(\delta / \delta^{*}\right)}{\left[1-\left(\delta / \delta^{*}\right)^{\frac{5}{2}}\right]^{\frac{1}{2}}}=1,435\left(m^{2} / R E^{* 2} v_{0}\right)^{\frac{1}{5}} .
$$

The overall time $T$ of the whole impact is given by:

$$
T=2 t^{*}=2.87\left(m^{2} / R E^{* 2} v_{0}\right)^{\frac{1}{5}} .
$$

From the curve $(F, t)$ the experimental value of $T$ is obtained, which, when inserted into (A10), provides the value of $E^{*}$ (see Equation (3)). Finally, using Equation (2), the value of the elastic modulus $E_{S}$ can be calculated.

\section{References}

1. Formia, A.; Serra, C.L.; Zerbinatti, M.; Tulliani, J.M. The plasters of the Sacro Monte of Varallo Sesia. From the characterization to the proposition of a restorative mix. Case Stud. Constr. Mater. 2014, 1, 46-52. [CrossRef]

2. Cizer, Ö.; Schueremans, L.; Serre, G.; Janssens, E.; Van Balen, K. Assessment of the compatibility of repair mortars in restoration projects. Adv. Mater. Res. 2010, 133-134, 1071-1076. [CrossRef]

3. Wiggins, D.E.; Klemm, A.J. Compatible repairs to stone built structures. Proc. Inst. Civ. Eng. Eng. Hist. Herit. 2014, 167, 196-207. [CrossRef] 
4. Grazzini, A.; Zerbinatti, M.; Fasana, S. Mechanical characterization of mortars used in the restoration of historical buildings: An operative atlas for maintenance and conservation. IOP Conf. Ser. Mater. Sci. Eng. 2019, 629, 1-7. [CrossRef]

5. Isebaert, A.; Van Parys, L.; Cnudde, V. Composition and compatibility requirements of mineral repair mortars for stone-A review. Const. Build. Mater. 2014, 59, 39-50. [CrossRef]

6. Binda, L.; Gambarotta, L.; Lagomarsino, S.; Modena, C. A multilevel approach to the damage assessment and the seismic improvement of masonry buildings in Italy. In Seismic Damage to Masonry Buildings; Bernardini, A., Ed.; Balkema: Rotterdam, Holland, 1999; pp. 179-194.

7. Binda, L.; Cantini, L.; Tedeschi, C. Diagnosis of Historic Masonry Structures Using Non-Destructive Techniques. In Nondestructive Testing of Materials and Structures; Buyukozturk, O., Tasdemir, M.A., Gunes, O., Akkaya, Y., Eds.; Springer Netherlands: Heidelberg, Germany, 2013; pp. 1089-1102. [CrossRef]

8. Grazzini, A. The important role of diagnostics for the structural recovery of historic buildings. Int. J. Arch. Eng. Technol. 2019, 6, 7-16. [CrossRef]

9. Invernizzi, S.; Lacidogna, G.; Carpinteri, A. Structural monitoring and assessment of an ancient masonry tower. Eng. Fract. Mech. 2019, 210, 429-443. [CrossRef]

10. Carpinteri, A.; Lacidogna, G. Damage monitoring of an historical masonry building by the acoustic emission technique. Mater. Struct. 2006, 39, 161-167. [CrossRef]

11. Carpinteri, A.; Lacidogna, G.; Pugno, N. Structural damage diagnosis and life-time assessment by acoustic emission monitoring. Eng. Fract. Mech. 2007, 74, 273-289. [CrossRef]

12. Carpinteri, A.; Invernizzi, S.; Lacidogna, G. Historical brick-masonry subjected to double flat-jack test: Acoustic emissions and scale effects on cracking density. Constr. Build. Mater. 2009, 23, 2813-2820. [CrossRef]

13. Cantini, L.; Bonavita, A.; Parisi, M.A.; Tardini, C. Historical analysis and diagnostic investigations in the knowledge acquisition path for architectural heritage. In Proceedings of the Congress in Structural Analysis of Historical Constructions-Anamnesis, Diagnosis, Therapy, Controls, Leuven, Belgium, 13-15 September 2016; Van Balen, V., Ed.; Taylor \& Francis Group: London, UK, 2016.

14. Grazzini, A. Sonic and Impact Test for Structural Assessment of Historical Masonry. Appl. Sci. 2019, 9, 5148. [CrossRef]

15. Chastre, C.; Ludovico-Marques, M. Nondestructive testing methodology to assess the conservation of historic stone buildings and monuments. In Handbook of Materials Failure Analysis with Case Studies from the Construction Industries; Hamdy Makhlouf, A.S., Aliofkhazraei, M., Eds.; Elsevier: New York, NY, USA, 2018; pp. 255-294, ISBN 978-0-08-101928-3. [CrossRef]

16. Vasconcelos, G.; Lourenço, P.B.; Alves, C.S.A.; Pamplona, G. Prediction of the mechanical properties of granites by ultrasonic pulse velocity and Schmidt hammer hardness. In Proceedings of the 10th North American Masonry Conference, St. Louis, MO, USA, 3-6 June 2007; Myers, B., Ed.; Masonry Society: Longmont, CO, USA, 2007.

17. Grazzini, A. In Situ Analysis of Plaster Detachment by Impact Tests. Appl. Sci. 2019, 9, 258. [CrossRef]

18. The Sacred Mounts of Piedmont and of Lombardy. Available online: www.sacrimonti.net (accessed on 10 February 2020).

19. Gonçalves, T.D.; Pel, L.; Delgado Rodrigues, J. Influence of paints on drying and salt distribution processes in porous building materials. Constr. Build. Mater. 2009, 23, 1751-1759. [CrossRef]

20. Bocca, P.; Grazzini, A.; Masera, D.; Alberto, A.; Valente, S. Mechanical interaction between historical brick and repair mortar: Experimental and numerical tests. J. Phys. Conf. Ser. 2011, 305, 1-10. [CrossRef]

21. Bocca, P.; Valente, S.; Grazzini, A.; Alberto, A. Detachment analysis of dehumidified repair mortars applied to historical masonry walls. Int. J. Arch. Herit. 2014, 8, 336-348. [CrossRef]

22. Grazzini, A.; Lacidogna, G.; Accornero, F. Delamination of plasters applied to historical masonry walls: Analysis by acoustic emission technique and numerical model. IPO Conf. Ser. Mater. Sci. Eng. 2018, 372, 1-7. [CrossRef]

23. Accornero, F.; Invernizzi, S.; Lacidogna, G.; Carpinteri, A. The Sacred Mountain of Varallo renaissance complex in Italy: Damage analysis of decorated surfaces and structural supports. In Acoustic, Electromagnetic, Neutron Emissions from Fracture and Earthquakes, 1st ed.; Carpinteri, A., Lacidogna, G., Manuello, A., Eds.; Springer: Heidelberg, Germany, 2015; pp. 249-264. [CrossRef]

24. Delgado Rodrigues, J. Conservation of stone monuments. From diagnostic to practice. In Proceedings of the MINBAR AL JAMIAA n 7-RIPAM 2005, Mekés, Maroc, 26-28 September 2005; pp. 287-295. 
25. Delgado Rodrigues, J.; Ferreira Pinto, A.; Rodrigues da Costa, D. Tracing of decay profiles and evaluation of stone treatments by means of microdrilling techniques. J. Cult. Herit. 2002, 3, 117-125. [CrossRef]

26. ASTM D2845 1995. Standard Test Method for Laboratory Determination of Pulse Velocities and Ultrasonic Elastic Constants of Rock; American Society for Testing Materials: West Conshohocken, PA, USA, 1995.

27. UNI EN 12504-4: 2005. Prove sul Calcestruzzo nelle Strutture-Parte 4: Determinazione della Velocità di Propagazione Degli Impulsi Ultrasonici (in Italian); Ente Nazionale Italiano di Unificazione: Milan, Italy, 2005.

28. Domede, N.; Parent, T.; Sellier, A. Mechanical behaviour of granite: A compilation, analysis and correlation of data from around the world. Eur. J. Environ. Civ. Eng. 2019, 23, 193-211. [CrossRef]

29. Bocca, P.; Scavia, C. The impulse method for the evaluation of concrete elastic characteristics. In Proceedings of the 9th International Conference on Experimental Mechanics, Copenhagen, Denmark, 20-24 August 1990.

30. Johnson, K.L. Contact Mechanics; Cambridge University Press: Cambridge, UK, 1985.

31. Deresiewicz, H. A note on Hertz Impact. Acta Mech. 1968, 6, 110-112. [CrossRef]

32. Dhawan, K.R.; Muralidhar, B. Relationship between static and two types of dynamic moduli for different rocks. Ind. Getech. J. 2015, 45, 341-348. [CrossRef]

33. Bocca, P.; Carpinteri, A.; Valente, S. On the applicability of fracture mechanics to masonry. In Proceedings of the 8th International Brick/Block Masonry Conference, Dublin, Ireland, 19-21 September 1988.

(C) 2020 by the authors. Licensee MDPI, Basel, Switzerland. This article is an open access article distributed under the terms and conditions of the Creative Commons Attribution (CC BY) license (http://creativecommons.org/licenses/by/4.0/). 